EPiC Series in Engineering
Volume 3, 2018, Pages 1131-1138
HIC 2018. 13th International
Conference on Hydroinformatics

\title{
Development of a water resources distribution and management tool (SPEHR); applied X. Lemaitre ${ }^{1}$, G.A. Corzo P. ${ }^{2}$, G.R. Santos G. ${ }^{\text {, H.A. Angarita }}{ }^{3}$. \\ ${ }^{1}$ Escuela Colombiana de Ingeniera, AK. 45 No. 205 59, Bogotá Colombia \\ ${ }^{2}$ IHE Institute for Water Education, Westvest 7 Delft, The Netherlands \\ ${ }^{3}$ The Nature Conservancy, Calle 67 No. 7-35, Bogotá, Colombia
}

Corresponding author: ximena.lemaitre@escuelaing.edu.co

\begin{abstract}
.
Water management is a complex problem that relates to human and physical variables that are very hard to predict, there is a cultural and social and human driven variables (Agricultural practices, Cities growth and others) that are hard to capture into the complex interactions of the water allocation and the hydrological system.

This research presents a new novel yet simple system that integrates information from river basin social and hydrological variables in an online system for decision support. The concept developed so far represents the Magdalena river system in Colombia, and allows to simulate and to share ideas. A communication bar includes a score of goodness provided by decision makers such that a level of agreement between actors can be achieved. Aside of this, the system is made open source such that other river basin can be set up and even other hydrological modelling systems can be plugged in.
\end{abstract}

\section{Introduction:}

Water management is a complex problem that relates to human and physical variables that are very hard to predict. Models to represent this complex problem have been developed ranging from decision support systems [1] to discussion support systems like the models based on serious gaming [2].

However, there is still cultural and social and human driven variables (Agricultural practices, Cities growth and others) that are hard to capture into the complex interactions of the water allocation and the hydrological system. Current models like WEAP [3], allow for a great variety of interactions, however, spatio-temporal information from agricultural practices, an interactive space for online decision making and quasi(social) oriented solutions are not available.

In Colombia, IDEAM's estimations of water demand from socio-economical activities is mainly represented by irrigation, domestic consumption, industrial, mining, livestock and services [4]. Also, Colombia have five macro-basins, one of them, is The Magdalena basin which gives water to the manly 
rate of demands in the country with a water efficiency of twenty seven liters per second per square kilometer. This system has interventions from multiple agencies. In 2010, the National Government, through the Ministry of Environment, Housing and Territorial Development (in accordance with article 12 of Law 1444 of May 4, 2011) adopted the National Policy for the Comprehensive Management of Water Resources (PNGIRH), with the support of the Netherland's embassy. In which the objectives, strategies, goals, indicators and strategic lines of action for the management of the water resource in the country were established over a 12-year timeline and six major components were drawn up: Supply, Demand, Quality of Irrigation, Institutional Strengthening and Governability[5].

Thus Colombia is in a process of change and awareness, in which, the new generations must actively participate and supporting this change. Currently in the world, learning techniques and intersectoral cooperation are being implemented, however, implementing this transition is challenging [3]. For the transition to be implemented, a social learning process needs to take place in which stakeholders became aware of the relationship between their own frames of reference and those of other [1].

This research presents a new novel yet simple system that integrates information from river basin social and hydrological variables in an online system for decision support. The concept developed so far represents the Coello basin system in Colombia, and allows to simulate and to share ideas. A communication bar includes a score of goodness provided by decision makers such that a level of agreement between actors can be achieved. Aside of this, the system is made open source such that other river basin can be set up and even other hydrological modelling systems can be plugged in. This paper also is a continuity of the investigation developed in WEAP for Coello Basin made before by Meiline Siahaan [6].

\section{Keywords:}

Coello basin, Open Sources, Water Allocation models. Water Demands, WEAP.

\section{Methods.}

\subsection{Python's model description}

The developed approach for the water allocation in Coello watershed in Colombia were based on 6 stages: (1) the lecture of the hydrology modeling catchment data; (2) Simulation of the irrigation demand; (3) simulation of the population demand; (4) Calculation of water supply delivered inside the catchment; (5) simulation of water allocation inside the Coello basin in Colombia. The five stages of the modeling approach and their relationships are illustrated in Figure 1.

The simulation for irrigation demand was simulated through the amount of irrigation area inside the crop yields in Coello, each area unit was assigned a rate of water use as is shown in the Equation1. Also, the simulation for population demand was simulate through a linear projection of the growth population for 10 years where for each habitant was assigned a rate use of water as is shown in Equation 2.

$$
D_{\text {Irr }}=R u * \text { Area_Unit }
$$

Where:

$D_{\text {Irr }}:$ Irrigation demand $\left[\mathrm{m}^{3}\right]$

$$
\begin{gathered}
\text { Ru: Rate of water use }\left[\frac{\mathrm{m}^{3}}{\mathrm{Ha}}\right] \\
\text { Area }_{\text {Unit }}: \text { Hectares }[\mathrm{Ha}] \\
D_{D}=R u * \text { \#population }
\end{gathered}
$$


Where:

$D_{D}:$ Domestic demand $\left[\mathrm{m}^{3}\right]$
Ru: Rate of water use $\left[\frac{\mathrm{m}^{3}}{\mathrm{Ha}}\right]$

\#population: population [percapita]

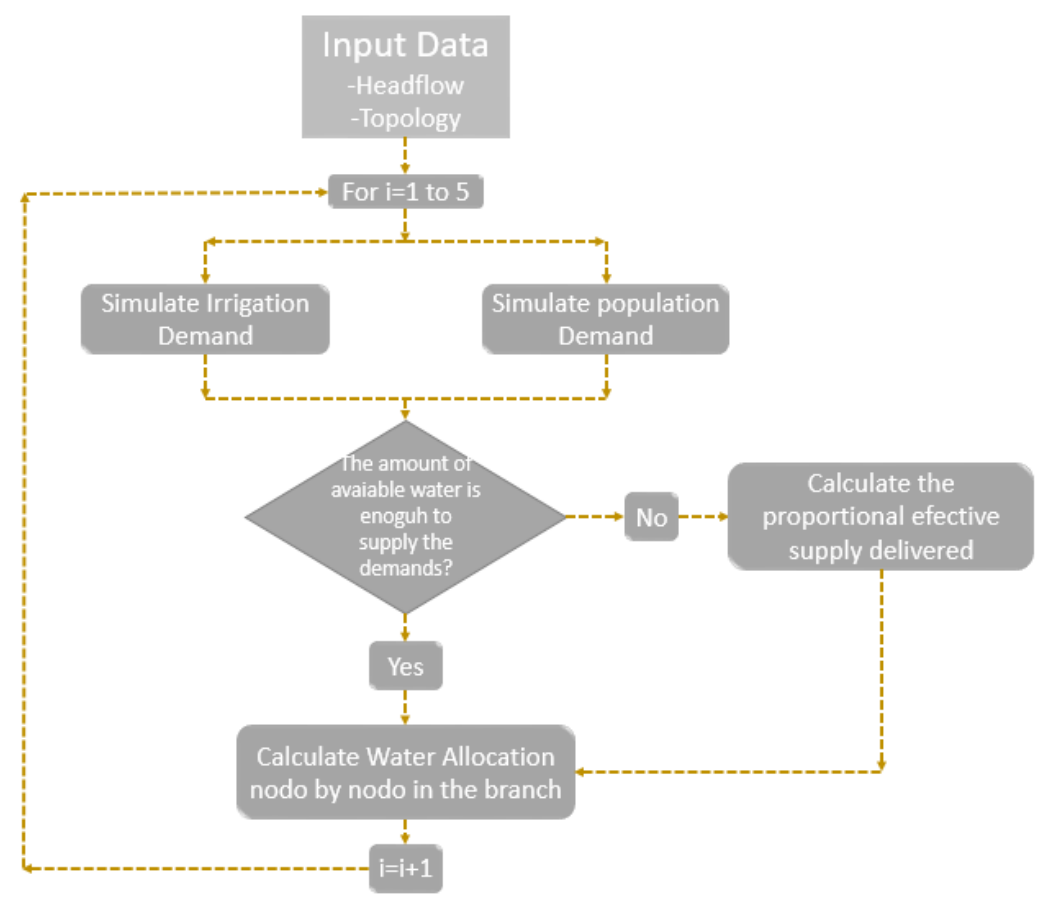

Figure 1 Stages of the developed modeling approach and their relationship in the water allocation in Coello watershed in Colombia

\section{a. Water allocation and mass balance equations}

To know the amount of water that the branch actually delivered, before calculate the mass balance equation on the branch, the program calculates the proportional effective supply demand per each demand site, this process will be described following:

Once the program has simulated the irrigation and population demand, and it also have the head flow per branch, the program evaluated if the amount of available water is enough to supply all the demands if not, the program calculates a proportional amount of water that will have the opportunity to delivered as follow:

Step 1: Verify if the volume available of water is enough for supply the demands in the branch

$$
\begin{gathered}
\text { if } V_{\text {in }}[i]<\operatorname{ReQ}[i] \rightarrow U D[i]= \\
\operatorname{Re} Q[i]-V_{\text {in }}[i] \text { else } U D[i]=0
\end{gathered}
$$

\section{Step 2: Calculate the unmet demand for} agriculture

$$
U D \operatorname{Irr}[i]=\frac{D_{i r r}[i]}{R e Q[i]} * U D[i]
$$

Step 3: Calculate the unmet demand for domestic demand

$$
U D D[i]=\frac{\operatorname{ReD}[i]}{\operatorname{ReQ}[i]} * U D[i]
$$


Step 4: Calculate the supply delivered for each node

$$
\text { SupplyReQD }=\operatorname{ReD}-U D
$$

SupplyReQIrr $=$ DIrr - UDIrr

Where

$V_{\text {in }}=$ Headflow (volume)

$R e Q=\sum D_{D}+D_{\text {Irr }}$

$U D=$ Unmet demand

UDIrr = unmet demand for agriculture

$U D D=$ Domestic unmet demand

SupplyReQD

$=$ Delivered Domestic Demand

SupplyReQIrr

$=$ Delivered Irrigation Demend

\subsection{WEAP model description}

WEAP (Water evaluation and Planning System) is a software tool for a water allocation planning which is developed by Stockholm Environmental Institute (SEI) to aid the water planner by simulation different scenarios of water resources management. The scenarios are created by proposing different water demands: hydrology, infrastructure, supply and resource, or water quality. This tool implement the water balance in a basin [6].

WEAP creates a comprehensive and integrated picture of a municipal, industrial and agricultural water use and respective supply sources. The model is useful to systematically identify all users and supply sources by amount and locations. All surface water supplies, ground water supplies, and interbasin supplies transfers may be included in the model. Major reservoir as well as local supply reservoir are modeled. Reporting of water supply includes: total supply resources; river, groundwater and local supply sources; evaporation losses from reservoir, rivers and tributaries retour flow; and surface and groundwater interaction[1].

Comparing supply and demand. Comparisons are made at a site level such as water treatment or wastewater treatment plant, or at an aggregate level such as city or country. Forecast of future demands may be made in several ways as compared with estimates supplies under drought or other hydrological conditions [7].

Mass balance reporting: the model can display a mass balance of withdrawals and uses at any river/tributary node, demand site, wastewater treatment facility and supply source[1].

The figure 3 shows the Coello basin model in WEAP, it also shows the interaction between nodes, rivers and tributaries. 


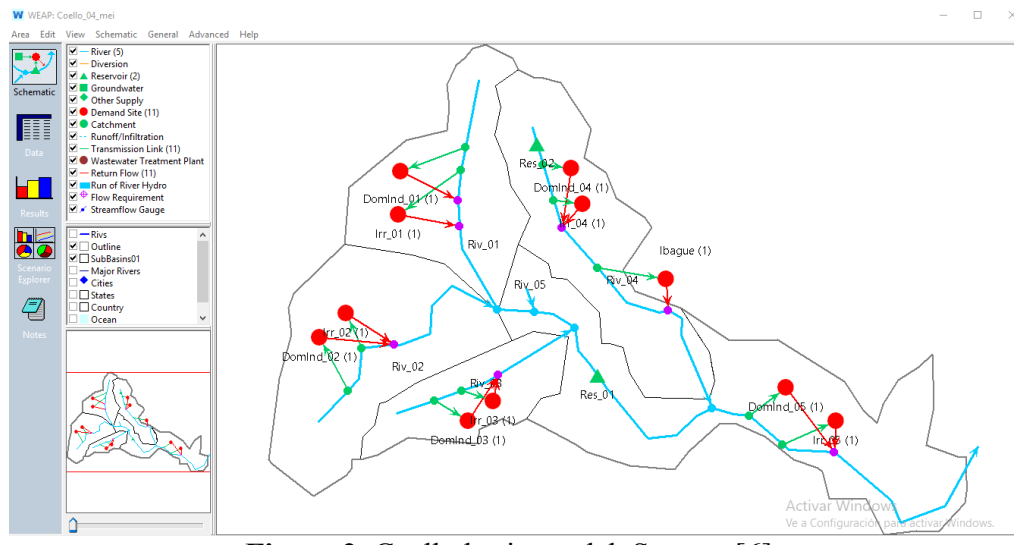

Figure 2 Coello basin model Source: [6]

\subsection{Validation method.}

The validation process was done through a comparison of the water volumes available in a period of time simulated by each model (WEAP \& Python). This comparison was verified through the method of the Root Mean Square Error (RMS). Therefore, for the validation of the simulation, it was selected a reference scenario, this reference scenario does not involve restrictions of reservoir storage or climate change, and it works with the actual data on the Coello basin.

In the second part of the simulation there was selected one more scenario, worked by Meiline on her WEAP model, which will be describe bellow:

- $\quad$ Current situation (Scenario Reference 1980-2013): this scenario uses the actual data.

- Impact of climate change and socio-economics changes (Scenario All change 19812013): this scenario is adapted from current situation scenario with several changes as listed in the following:

1. Increasing of potential crop evapotranspiration

2. Increasing water demand

3. Changing head flow by using the most extreme projection

4. Increasing domestic and industrial factor as the changing projection of socio economic.

The input data used for the python model was proportionated in CVS files, which contains the information below:

- A daily series of flow in cubic meters per second for the reference scenario.

- A daily series of flow in cubic meter per second for the All change scenario.

- A monthly series of irrigation demand in cubic meters per second for references and all change scenario.

\section{Case of Study}

Coello River is located in the southwest of Bogota City, flows through Tolima Department and ends in the Magdalena River. The Coello Basin has several sub basin, they are Rio Toche, Rio Coello, Rio Combeina, Rios Barmelon, Rio Cocora and Quebrada Gallego. Water in Coello basin is mainly used for industrial, agricultural, livestock and public water demand [8]. Ibague as the capital of Tolima Department relies its water demand for domestic and industrial on the Coello basin. 
For development of the model were used two CVS files provided by the WEAP model of Meiline Siahaan. One of those CVS files had a daily time series of flow in cubic meter per second and the second one had a monthly requirement of water for irrigation, both file belongs to the Coello basin in Colombia and were obtained from a meteorological IDEAM's stations.

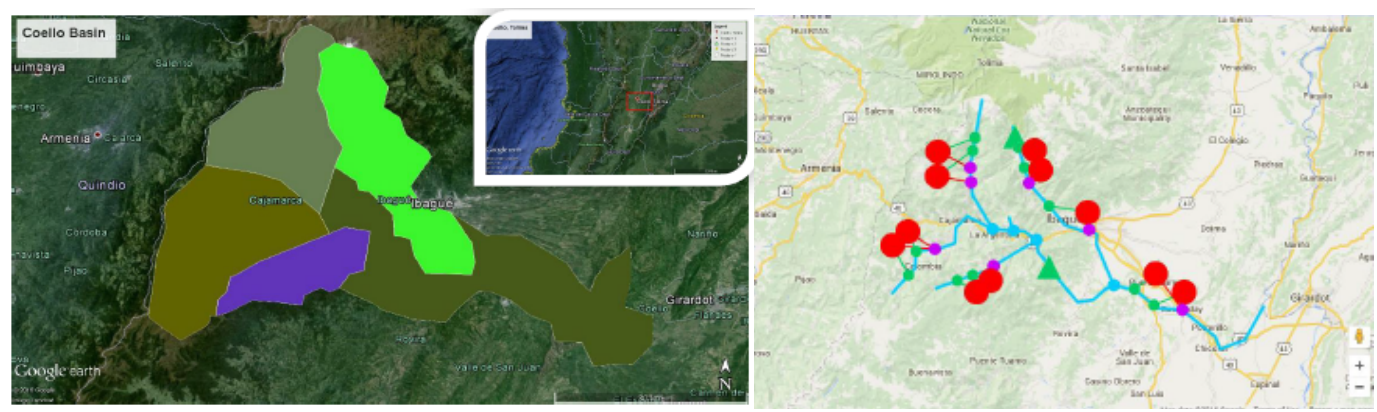

Figure 3 Coello Basin Source: [6]

\section{Results}

The Python model was compared with the WEAP model in terms of water volume available below the final demand point. Similarly, supply and unmet demands for the all the branches were compared.

As show in the figure 4, the behavior of the output hydrographs, over the Reference Scenario, is similar, both have the peak at the same time of the year with an error of $0.3 \%$ in the amount of available water in the year. Similarly, both hydrographs present a bimodal behavior through the year.

At the same time, as you can see in the figure 5, over the All Change Scenario, the behavior of the hydrographs is similar too, but in this case, they present just one peak through the year with an error of $0.4 \%$ in the amount of water.

Similarly, when the comparison within the river 2, one of the branches of Coello basin, was made it was obtained, for the Reference Scenario and All Change Scenario, an error of $0.17 \%$ and $2 \%$ for the supply delivered and unmet demand for domestics demands respectively and an error of $1 \%$ and $0.5 \%$ for the supply delivered and unmet demand for irrigation demands respectively.
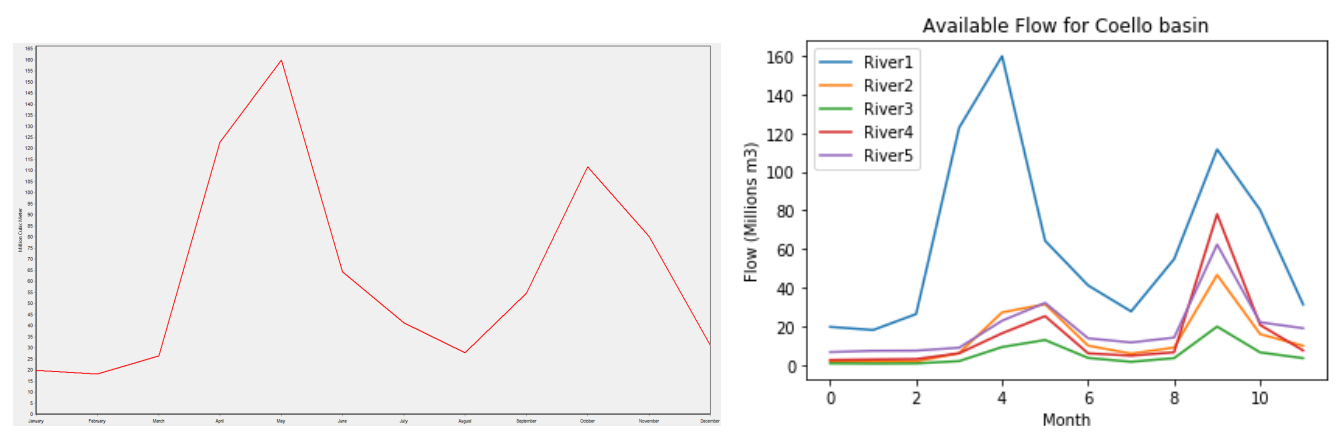

Figure 4 Water available at the exit of Coello basin. Scenario Reference a) WEAP model b) Python model 

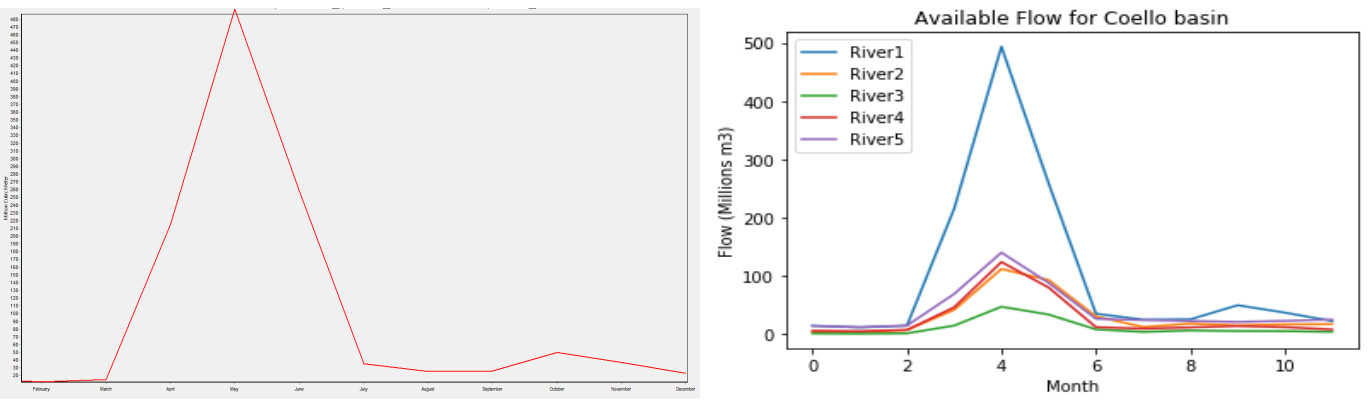

Figure 5 Water available at the exit of Coello basin. Scenario All change a) WEAP model b) Python model

\begin{tabular}{|c|c|c|c|c|c|}
\hline Month & HeadflowR2 & Domestic & Demand & Irrigation & Demand \\
\hline Jan & 12.588 & & 4.717 & & 9.196 \\
\hline Feb & 9.677 & & 4.261 & & 6.131 \\
\hline Mar & 12.053 & & 4.717 & & 2.682 \\
\hline Apr & 44.064 & & 4.565 & & 0.000 \\
\hline May & 114.100 & & 4.717 & & 0.000 \\
\hline Jun & 96.941 & & 4.565 & & 1.916 \\
\hline Ju1 & 36.158 & & 4.717 & & 3.449 \\
\hline Ago & 19.820 & & 4.717 & & 5.365 \\
\hline Sep & 22.291 & & 4.565 & & 1.916 \\
\hline Oct & 18.481 & & 4.717 & & 1.150 \\
\hline Nov & 20.995 & & 4.565 & & 1.916 \\
\hline Dic & 24.373 & & 4.717 & & 4.981 \\
\hline Supply & $y$ delivered & Domestic & Supply & delivered I & Irrigation \\
\hline & & 4.268 & & & 8.320 \\
\hline & & 3.968 & & & 5.709 \\
\hline & & 4.717 & & & 2.682 \\
\hline & & 4.565 & & & 0.000 \\
\hline & & 4.717 & & & 0.000 \\
\hline & & 4.565 & & & 1.916 \\
\hline & & 4.717 & & & 3.449 \\
\hline & & 4.717 & & & 5.365 \\
\hline & & 4.565 & & & 1.916 \\
\hline & & 4.717 & & & 1.150 \\
\hline & & 4.565 & & & 1.916 \\
\hline & & 4.717 & & & 4.981 \\
\hline
\end{tabular}

\begin{tabular}{|c|c|c|c|c|}
\hline Month & HeadF1owR2 & Domestic & Demand & Irrigation Demand \\
\hline Jan & 5.812 & & 1.577 & 12.765 \\
\hline Feb & 5.212 & & 1.475 & 8.510 \\
\hline Mar & 4.768 & & 1.577 & 3.723 \\
\hline Apr & 6.765 & & 1.526 & 0.000 \\
\hline May & 27.882 & & 1.577 & 0.000 \\
\hline Jun & 33.929 & & 1.526 & 2.659 \\
\hline JuI & 14.008 & & 1.577 & 4.787 \\
\hline Ago & 11.758 & & 1.577 & 7.446 \\
\hline Sep & 11.508 & & 1.526 & 2.659 \\
\hline oct & 48.399 & & 1.577 & 1.596 \\
\hline Nov & 18.481 & & 1.526 & 2.659 \\
\hline Dic & 15.428 & & 1.577 & 6.914 \\
\hline \multicolumn{2}{|c|}{ Supply delivered } & Domestic & \multirow[t]{13}{*}{ Supply } & delivered Irrigation \\
\hline$\theta$ & & 0.639 & & 5.173 \\
\hline 1 & & 0.770 & & 4.442 \\
\hline 2 & & 1.418 & & 3.349 \\
\hline 3 & & 1.526 & & 0.000 \\
\hline 4 & & 1.577 & & 0.000 \\
\hline 5 & & 1.526 & & 2.659 \\
\hline 6 & & 1.577 & & 4.787 \\
\hline 7 & & 1.577 & & 7.446 \\
\hline 8 & & 1.526 & & 2.659 \\
\hline 9 & & 1.577 & & 1.596 \\
\hline 10 & & 1.526 & & 2.659 \\
\hline & & 1.577 & & 6.914 \\
\hline
\end{tabular}

Figure 6 Demand and Supply delivered demand for River 2 a) Scenario Reference b) Scenario All change

\section{Conclusions}

The model developed in python managed to recreate the results obtained with WEAP models in a satisfactory way since the errors calculated are below $2 \%$. This means that the program could obtained similar water allocation process than WEAP simulating the same behavior of the water demand, supply delivered, unmet demand and above all the behavior of the hydrograms at the end of each branch and at the end of the chosen basin.

This model does not have the GIS functionality, therefore the user must enter the data manually and check the mass balance equations for each branch. After that the user will be able to check the same results that was show before.

Additionally, within the process of water distribution in WEAP, it was observed that once this program makes the mass balance, if at some point it fails to supply the demand completely, it assumes that the precipitation was taken in a timely manner. Therefore, this program has continued its development, improving the spatial distribution of rainfall through current rainwater runoff transformation models, and also improving functionalities such as the simulation of the irrigation demand and the GIS functionalities. 


\section{References.}

[1] W. Johnson, Q. Williams, and P. Kirshen, "WEAP: A Comprehensive and Integrated Model of Supply and Demand," Georg. Water Resour. Conf., pp. 291-293, 1995.

[2] J. Craven, H. Angarita, G. A. Corzo Perez, and D. Vasquez, "Development and testing of a river basin management simulation game for integrated management of the Magdalena-Cauca river basin," Environ. Model. Softw., vol. 90, no. January, pp. 78-88, 2017.

[3] C. Figueroa and M. Escobar, "Modelación hidrológica del recurso hídrico en la subcuenca del Río Aipe en Colombia 'Ríos del páramo al valle, por urbes y campiñas," Sei, no. Figura 1, pp. 1-4, 2015.

[4] IDEAM, "Estudio Nacional del Agua 2010,” Estud. Nac. del Agua 2010, p. 69, 2010.

[5] IDEAM, INVEMAR, SINCHI, IIAP, and IAvH, Informe del Estado del Medio Ambiente y de los Recursos Naturales 2015. Documento Sintesis. 2016.

[6] M. H. Siahaan, "Development of a Web-based Water Allocation Model: Case Study of Coello Basin, Colombia," no. April, 2016.

[7] D. Yates, D. Purkey, J. Sieber, A. Huber-Lee, and H. Galbraith, "WEAP21-A Demand-, Priority-, and Preference-Driven Water Planning Model," Water Int., vol. 30, no. 4, pp. 501-512, 2005.

[8] Ideam, “Zonificación y Codificación de Cuencas Hidrográficas,” p. 46, 2013. 